\title{
DOR E TECNIFICAÇÃO NO CONTEMPORÂNEO CULTO AO CORPO*
}

\author{
GISELLE TORRI $^{* *}$ \\ JAISON JOSÉ BASSANI ${ }^{* * *}$ \\ AlexandRe Fernandez VAZ ${ }^{* * * *}$
}

\section{RESUMO}

O culto contemporâneo ao corpo entrelaça discursos pela promoção da saúde com dispositivos de conformação somática vinculados, entre outros, à performance, à instrumentalização orgânica e à celebração da juventude. Nesse sentido, pesquisamos relações entre práticas de modelação corporal - entendidas como intervenções tecnológicas sobre o corpo -, políticas de consumo e juventude. O estudo focou a condição juvenil e foi realizado em uma academia de ginástica e musculação da litorânea Florianópolis. Para tanto, utilizamos procedimentos etnográficos, como análise de material gráfico, observações participantes, entrevistas, diários de campo, descrições de atores e considerações sobre a subjetividade dos pesquisadores. Os resultados dizem respeito ao consumo de corpos, conseqüência do culto a técnicas somáticas.

PALAVRAS-CHAVE: embelezamento - educação do corpo - indústria cultural técnicas corporais.

\section{INTRODUÇÃO}

$\Lambda$ busca da juventude eterna é uma das freqüentes fantasias associaAdas à utopia da imortalidade. Os investimentos na produção das mais diversas técnicas para a manutenção da beleza e da saúde, encarados como atributos essencialmente dos jovens, parecem constituir algo constante em nossa história. Como destacou Sant'Anna (2002), diversos museus e exposições sobre a vida dos povos antigos mostram

* O trabalho apresenta resultados parciais do projeto Teoria Crítica, Racionalidades e Educação, financiado pelo CNPq.

** Especialista em Educação Física Escolar.

*** $\quad$ Aluno do Doutorado no Programa de Pós-graduação em Educação da Universidade Federal de Santa Catarina (PPGE/CED/UFSC).

**** Doutor em Ciências Humanas e Sociais pela Universidade de Hannover, Alemanha, e pesquisador CNPq. 
pincéis utilizados na pintura do rosto, pentes sofisticados e recipientes para guardar tinturas e pós considerados rejuvenescedores. Ao mesmo tempo, a educação e os cuidados com o corpo remontam aos períodos civilizadores da Grécia Clássica e da República Romana.

As preocupações com a saúde e, sobretudo, com a beleza, parecem ter alcançado grande importância também na modernidade e especialmente no tempo contemporâneo. Uma das expressões mais significativas dessa centralidade do corpo na forja das subjetividades - que também são construções modernas - está relacionada ao consumo, cada vez maior, de espaços e intervenções tecnológicas destinados à prática de atividades corporais vinculadas a certo culto do corpo, como as academias de ginástica e musculação, as clínicas para tratamento estético e consultórios médicos de cirurgia plástica.

Nesse mesmo quadro destaca-se ainda o lugar que o corpo ocupa em um dos mais característicos espaços dos processos da indústria cultural: as revistas ilustradas que semanalmente trazem grande quantidade de informações para modelar, cuidar e embelezar os corpos de homens e mulheres. Tudo isso parece indicar e conformar uma pedagogia do corpo presente em vários tempos e espaços da sociedade contemporânea e cujas predições buscam informar como o corpo não pode deixar de ser.

A busca por um corpo mais delineado e retesado, com músculos mais espessos e menos gordura - na linguagem das academias, mais "durinho" e "sequinho" -, vinculado, essencialmente, aos mutantes e efêmeros padrões de beleza, parece incidir principalmente - mas não exclusivamente - sobre as mulheres e, dentre elas, especialmente as mais jovens.

Enquanto podemos observar uma preocupação histórica, particularmente moderna, de prevenção à feiúra, a tônica hoje parece ser não somente corrigir as "imperfeições" que aparecem com o avançar da idade, mas prevenir o seu surgimento (SANT'ANNA, 1995). Cada vez mais cedo se lança mão das mais diversas técnicas para manter-se bela (as exigências, como dito, são mais rigorosas sobre as mulheres) e ou adquirir a forma física adequada. ${ }^{1}$ Exemplo disso é a progressiva procura de adolescentes por academias de ginástica e musculação e o crescente número de revistas direcionadas a esse público que, a cada verão ou período de volta às aulas, trazem novas recomendações de roupas e acessórios para se usar na escola, dicas de embelezamento e de exercícios físicos. ${ }^{2}$ 
É dentro do universo dessa temática que realizamos uma investigação cujo objetivo foi estudar a relação entre as práticas de modelação corporal em uma academia de ginástica e musculação e os imperativos da indústria cultural no que se refere ao corpo de jovens rapazes e moças, relacionados, especialmente, aos modelos corporais desejados, almejados e, de alguma forma, alcançados por eles.

A investigação foi realizada em uma academia de ginástica e musculação situada em bairro urbano na cidade de Florianópolis, localizada nas imediações de uma universidade pública e que atende principalmente à população dos bairros circunvizinhos àquela. Foram realizadas intensas e sistemáticas observações das aulas de ginásticas e das seções de musculação, inclusive participantes, entrevistas com alunos(as) e uma professora da academia, além de outros procedimentos etnográficos durante oito semanas.

Nas próximas páginas oferecemos, primeiramente, uma breve descrição do campo investigado, procurando mostrar algumas de suas particularidades, mas também aquilo que o torna semelhante a outros espaços privilegiados de educação do corpo hodiernamente. Na seqüência, apresentamos parte dos resultados da pesquisa, conseqüência do cruzamento entre os objetivos da investigação e as expressões próprias do objeto sobre o qual nos debruçamos. Por meio deles estabelecemos uma narrativa sobre algumas das representações dos adolescentes a respeito do corpo, com especial interesse nas estratégias tecnológicas que sobre este incidem, em especial na relação entre dor, privação $e$ sofrimento. Esse movimento procura mostrar o papel da dor mediada tecnologicamente nos investimentos sobre o corpo, a positividade que ela encontra como legitimadora da violência e apaziguadora das consciências ao promover a convicção do dever cumprido. Nas considerações finais, retomamos a questão para interpretá-la em um novo plano e na direção da delimitação de uma possível pedagogia dos corpos nas academias de ginástica e musculação.

\section{SOBRE O CAMPO}

Situada num bairro urbano da cidade de Florianópolis, nas imediações de uma grande universidade pública, a academia que foi campo 
da pesquisa localiza-se na sede de uma associação esportiva dos funcionários da mesma universidade, com serviços oferecidos ao público em geral, constituído por muitos jovens, a maioria deles universitária, estudantes do Ensino Médio de colégios próximos, além de alguns moradores dos bairros vizinhos.

É uma academia de pequeno porte e nosso interesse a ela voltouse, justamente, para que pudéssemos investigar em que circunstâncias os cuidados com o corpo se colocam também em ambientes menos glamourosos. O espaço consiste em um salão de $362 \mathrm{~m}^{2}$, dividido em duas salas de ginástica, uma seção de musculação, dois banheiros e uma pequena recepção na entrada da academia. A divisão entre a principal sala de ginástica, localizada em posição privilegiada, e aquela destinada à musculação, é estabelecida por uma parede divisória cuja parte superior é de vidro, o que possibilita observar as aulas.

Essa sala possui um pequeno palco para os(as) professores(as), além de outros materiais utilizados para o seu desenvolvimento, como steps, barras, anilhas e colchonetes. Suas paredes são de concreto liso, pintadas da cor branca, e estão em bom estado de conservação, assim como o piso da sala, que é de madeira. Existem vários cartazes colados nas paredes, a maioria deles faz propaganda das modalidades de ginástica oferecidas. Há também um mural onde são pendurados cartazes com dicas de alimentação e curiosidades sobre atividades corporais. Freqüentemente eles são renovados, geralmente quando se está na semana de lançamento de uma coreografia ou até mesmo de uma modalidade nova, trazendo frases de motivação e convidando os freqüentadores para as conhecerem.

A seção de musculação compreende um terço do total da sala da academia. Muitos dos aparelhos não são novos, de diversas marcas, tendo alguns passado por reformas, mas ainda se apresentando em boas condições de uso. Devido ao pequeno espaço, os alunos e alunas não têm um lugar específico para fazer exercícios abdominais e alongamento e acabam realizando-os na pequena sacada que também pertence à academia, na sala de ginástica - nos intervalos de aula - e até mesmo no corredor ao lado da recepção. Há também alguns aparelhos para exercícios abdominais, mas estes, por não terem um espaço específico, cada dia se encontram em um lugar diferente. As paredes, como as da sala de ginástica, são de concreto liso e pintadas da cor branca, também com muitos cartazes, tanto sobre as 
modalidades de ginástica como com informações sobre alguns exercícios e também sobre o uso obrigatório de toalha e a proibição da realização de atividades de chinelos e roupas jeans.

A academia dispõe no total de onze funcionários, incluindo o sócio-gerente, dos quais quatro são responsáveis pela musculação e outros quatro pela ginástica, um pela limpeza, um recepcionista e uma estagiária de nutrição.

Algumas características do público que freqüenta a academia, tais como idade e maior ou menor presença ou ausência de gordura e massa muscular, acabam influenciando na distribuição e ocupação dos horários de funcionamento. Geralmente o público mais maduro opta pelos horários mais "tranqüilos", de manhã, próximo ao meio-dia ou no início da tarde, acontecendo o contrário com os jovens que freqüentam a academia com mais assiduidade no final da tarde e início da noite, horários de maior movimento.

Ainda no que diz respeito ao público, especialmente em relação aos freqüentadores do sexo masculino, a grande maioria é constituída de pessoas que poderíamos considerar, na tipologia ${ }^{3}$ estabelecida por Sabino (2000, p. 82-83), como comum. Sua principal característica seria a aparente falta de massa muscular. É aquele indivíduo que é "gordo", "gordinho", "muito gordo", "magro", "muito magro", "nem gordo nem magro", "que tem gordura localizada", enfim, a grande maioria das pessoas que não se aproxima do ideal atlético e de beleza masculina presente em nosso imaginário social.

Entretanto, existe um grupo relativamente significativo de indivíduos que facilmente poderia ser enquadrado na categoria veterano. Estes treinam geralmente no horário da noite e apresentam uma dinâmica autônoma, uma vez que praticamente não seguem a ficha de treino fornecida pelo avaliador físico (inclusive, raramente fazem avaliação física) e dispensam os conselhos e ajuda dos(as) professores(as) de musculação.

No que diz respeito às freqüentadoras, mais presentes que os homens, e levando em consideração a mesma tipologia estabelecida por Sabino (2000) para esses, mas observando as devidas diferenças de gênero no que se refere ao ideal de beleza e das características físicas supostas como femininas, ${ }^{4}$ podemos afirmar que a maioria delas é também do tipo comum. Entretanto, a presença do tipo ideal veterana é mais 
significativa do que entre os freqüentadores, ou seja, encontramos um maior número de mulheres que se aproximariam da idealização mais comum da beleza feminina, ao passo que o modelo de beleza masculina é encontrado em menor número entre os freqüentadores.

Se por um lado, as diferenças entre homens e mulheres influenciam na ocupação e distribuição de forma diferenciada dos horários de funcionamento da academia pesquisada, por outro, elas não constituem elemento diferenciador importante em um aspecto do contemporâneo culto do corpo, a saber, a "naturalização" da dor e do sofrimento como algo inerente às técnicas de modelação corporal.

\section{DOR, PRIVAÇÃO E SACRIFÍCIO}

O enfrentamento da dor, do sofrimento, do sacrifício e da privação é freqüentemente encarado como algo corriqueiro e "normal" por parte dos freqüentadores de academias. Esses elementos, constituintes da lógica de treinamento esportivo, por sua vez presente com força cada vez maior nas academias, parecem ser menos um efeito colateral nesse processo de busca pelo embelezamento e pelo ideal das formas do que verdadeiros coadjuvantes dessa batalha constante pelo "aperfeiçoamento" corporal (HANSEN; VAZ, 2004). A dor, antes de ser entendida como uma expressão irrenunciável da corporalidade, passa a representar um obstáculo a ser suportado, superado, ou, inclusive, tornado fonte de prazer (VAZ, 2001).

Como se sabe, a dor não é uma "aliada" do treinamento corporal, mas, do ponto de vista subjetivo, o inimigo a ser combatido, superado, suportado, ignorado - ou ainda, num registro mais fronteiriço, a experiência a ser glorificada, desejada, certificação de que de fato se está indo além dos limites e que, portanto, há mérito na dilaceração do próprio corpo (HANSEN; VAZ, 2004, p. 141-142).

Identificamos certa "naturalização" da dor e do sofrimento corporal, um componente identificador - mas também legitimador, como se verá em seguida - do alcance das aspirações dos freqüentadores da academia, já que se trata de uma "dor boa", sinal de "resultados". O modo como a dor é representada, como algo inerente à prática de modelação corporal, foi confirmada nas respostas dos adolescentes entrevistados. 
Quando perguntados se costumavam sentir dor durante os exercícios de musculação ou nas aulas de ginástica, responderam da seguinte forma:

Ah, depende, né? Quando eu tô com o peso muito alto, essas coisas, que dá aquela ardência e não dá muito mais pra fazer, o músculo tá trabalhando ... e depois do exercício eu também fico sentindo, e até no outro dia às vezes quando eu pego muito peso...

[Perguntamos se ela considera normal sentir dor]... Ah, eu acho que é, tá trabalhando, né?, daí acho que é normal, não sei, não tenho muito o que falar, acho que todo mundo sente essa dor. Então, pra... todo mundo quer ficar bonito, quer malhar o corpo sente dor, então eu acho normal (Juliana, estudante, 15 anos).

$\mathrm{Ah}$, musculação, sinto, porque às vezes tem muita repetição, o peso assim, né?... o começo é agradável, mas fazendo as repetições vai doendo né... no Pump, o braço, ui, lateja (risos).

[Perguntamos se ela vê a dor de forma positiva ou negativa]...positiva, eu penso, porque se os outros conseguem por que eu não vou conseguir, né?... Tô melhorando, tô fazendo pra mim... [Perguntamos se ela sente dor em todas as aulas]...Ué, depende da aula, né?, na [ginástica] localizada, a maioria eu sinto dor, Gap, Pump, ai é muito bom! (suspiro).

[Perguntamos o que os professores falam a respeito da dor]... tá doendo, tá doendo, mas o meu também tá doendo, entendeu?, eles falam, continua, já tá acabando (Aline, estudante, 17 anos).

Outra característica que a dor e o sofrimento adquirem nesses ambientes de educação do corpo vincula-se a certo caráter legitimador, a um 'preço a ser pago pelo corpo 'perfeito', justificando-se, assim, como símbolo de merecimento pelo ideal atingido" (HANSEN; VAZ, 2004, p. 144). Não apenas sentir, mas mostrar a dor parece ser algo importante, mesmo que, às vezes, seja algo ironizado pelos colegas. Permanece a crença no conhecido ditado anglo-saxão, escutado frente aos muitos quilos de peso prestes a serem levantados por um aluno na musculação: no pain, no gain.

Ainda nesse quadro, ganha força o constante processo de incitamento a suportar e, por vezes, superar a dor sentida durante a execução dos exercícios das aulas de ginástica. Não foram poucas as ocasiões em que observamos os professores utilizando estratégias para incentivar, especialmente da metade para o final das aulas, as alunas a transforma- 
rem o desconforto provocado pela dor em estímulo contra as expressões de sofrimento: "eu sei que está doendo, mas vamos comigo até o fim", "tá queimando, né?", "esmaga esse abdômen!", "vamos lá, vocês conseguem!", "mais intensidade agora", "energia, galera!".

Esse expediente ganha novos contornos quando é demandada a questão da beleza física, especialmente entre as mulheres, pois, além das frases de motivação, surgem também ameaças - "quem não for até o final vai se encher de celulite" - e mesmo uma chantagem: antes de iniciar uma música da aula de Body Pump, um professor perguntou se as alunas queriam ir à praia no final de semana, alertando que o exercício, então, deveria ser feito com mais peso e mais intensidade. Aquelas que porventura não desejassem ir, poderiam fazer a seqüência de exercícios de forma mais leve. E complementou: quem quisesse usar saia curta e mostrar as coxas, que se exercitasse ainda com mais vigor. A maioria das meninas obviamente realizou o exercício com mais intensidade.

Há aqui também certa relação entre crença e esclarecimento. Como relatamos anteriormente, a maioria do público da academia constitui-se de estudantes universitários e também do Ensino Médio, o que nos fazia imaginar que seriam menos suscetíveis aos apelos não racionais e que tratassem das questões relacionadas ao corpo de maneira mais esclarecida. Entretanto, o desejo de pertencer ao grupo seleto de quem possui um corpo considerado bonito e "sarado" faz com que mito e crença se misturem ao conhecimento científico nos discursos dos professores e na ação dos alunos. É evidente que tanto os professores quanto, nesse caso, as alunas, sabem que fazer uma série a mais, ou, então, algum tipo de simpatia - um ato mágico ${ }^{5}$ não irá proporcionar melhores resultados. No entanto, a sensação que fica é de que, conforme destacado por Silva (2003, p. 13), essa auto-ilusão representa uma espécie "de alívio em enganar a si mesmo com o resultado desejado, mas não necessariamente alcançado".

Outra questão importante, e relacionada às privações, diz respeito ao fato de um dia específico ser considerado o de "expurgar" os males do final de semana - sejam esses os da comida em excesso ou da inatividade física. Trata-se da segunda-feira, geralmente o dia de maior movimento na academia, quando se deve aliviar a "consciência pesada", descontando os excessos dos dias parados, vencendo a preguiça 
de acordar cedo e treinar em dobro. Um fragmento de nosso diário de campo expõe claramente essa questão:

Uma aluna conversa com um colega da musculação e comenta que comeu muito no final de semana, e, além do mais, tomou cerveja. Então tinha muito para malhar nessa segunda-feira. Em seguida, ela diz: "chega uma hora em que a consciência pesa". Outras duas alunas comentam, durante os seus exercícios de abdominais, que comeram muito no final de semana, e que agora precisavam "descontar".

Isso se vincula ao que Sabino (2000, p. 90) chama de uma "dedicação quase que monástica" que é exigida daqueles que desejam transformar seus corpos. O fato de ausentar-se de um dia de treino e de deixar de fazer exercícios físicos "por preguiça" é considerado falta grave. É como se uma abstenção fizesse com que todos os outros dias empenhados na busca do corpo ideal fossem prejudicados, deixando os resultados ainda mais distantes. Na mesma direção, Hansen e Vaz (2004) destacam que essa dedicação aproxima-se de uma espécie de vício, que parece acometer muitos freqüentadores:

Esta submissão a privações e a uma árdua rotina de exercícios muitas vezes torna-se algo imprescindível, um "vício" [...] do qual não querem se livrar, a ponto de relatarem sentimentos de culpa e de frustração tanto pelas falhas relacionadas à regularidade de suas respectivas freqüências na academia, quanto pela não obtenção dos resultados esperados (HANSEN; VAZ, 2004, p. 143).

Submissão e dedicação também são exigidas pelos alunos aos professores da academia, ao manifestarem o desejo de querer vê-los "sofrer" ou cobrando que treinem - um professor precisa apresentar vasto capital corporal - com mais peso.

\section{CONSIDERAÇÕES FINAIS}

A relação dos freqüentadores da academia - e entre estes, os adolescentes - com a dor e o sofrimento corporal estrutura-se como um processo de "naturalização", algo visto como "normal", componente identificador 
e legitimador do alcance das aspirações dos marombeiros, uma espécie de "preço a ser pago pelo corpo "perfeito" (HANSEN; VAZ, 2004, p. 144).

Ainda dentro desse quadro, identificamos um elemento que ganha contornos específicos no campo investigado, qual seja, o constante processo de incitamento de alunos a suportarem e superarem - e mesmo apreciarem - a dor sentida durante a execução dos exercícios das aulas de ginástica. Como procuramos mostrar, é freqüente o uso de diversas estratégias por parte dos professores para incentivar, especialmente da metade para o final das aulas, os alunos e alunas a transformarem o desconforto provocado pela dor em estímulo a mais e garantia do dever cumprido.

Outra questão importante relacionada às privações na busca pelo corpo "perfeito" diz respeito ao fato de a segunda-feira ser o dia de "expurgar" os males do final de semana. Este é o dia de maior movimento na academia e ficou mesmo a impressão de que todos os alunos e alunas apareciam para treinar. Dia também em que todos "pegam pesado" por conta da culpa pelo final de semana: mais treino e menos comida como antídotos contra os ataques do sedentarismo e da gordura. No calendário do evangelho do fitness a segunda-feira é dia santo, momento de arrependimento, confissão e penitência.

As academias de ginástica e musculação configuram espaços nos quais se forja uma pedagogia do corpo - como ele deve, mas, sobretudo, como não deve ser - que, no que se refere à adolescência, ganha ares de importante investimento no mercado afetivo e na reafirmação do que se espera dos ideais de masculinidade e feminilidade. São também espaços de visibilidade, de exposição corporal e de preparação para que esta se dê do lado de fora das academias, desde que, obviamente, as medidas corporais autorizem o espetáculo.

Pain and technification in contemporary cult of the body

\begin{abstract}
Contemporary Cult of the Body intertwines discourses that promote wellness with somatic conformity devices that are linked, among others, to performance, to organic instrumentalization, and to the celebration of youth. In this sense, we have researched the relations between body modeling practices - here understood as technological interventions on the body -, consumer policies, and youth. The research has focused on youngsters and it was developed in a gym in the coast city of Florianopolis, in
\end{abstract}


Brazil. Ethnographic procedures were used, such as the analysis of graphic material, participant observation, interviews, logs, description of actors, and considerations on the subjectiveness of the researchers. The results we show up regard to body consumption as a consequence of the cult of somatic techniques.

KEYWORDS: human beautification - body education - culture industry - body techniques.

Dolor y tecnificación en el contemporáneo culto al cuerpo

\section{RESUMEN}

O culto contemporáneo al corpo entrelaza discursos por la promoción de la salud con dispositivos de conformación somática vinculados, entre otros, a la performance, a la instrumentalización orgánica y a la celebración de la juventud. En ese sentido, investigamos relaciones entre prácticas de modelación corporal - entendidas como intervenciones tecnológicas sobre el cuerpo -, políticas de consumo y juventud. El estudio dio enfoque a la condición juvenil y fue realizado en una academia de gimnasia y musculación de la costanera Florianópolis. Para ello, utilizamos procedimientos etnográficos, como análisis de material gráfico, observaciones participantes, entrevistas, diarios de campo, descripciones de actores y consideraciones sobre la subjetividad de los investigadores. Los resultados, que presentamos en el presente trabajo, respectan al consumo de cuerpos, consecuencia del culto a técnicas somáticas.

PALABRAS-CLAVE: embellecimiento - educación del cuerpo - industria cultural técnicas corporales.

\section{NOTAS}

1 Segundo reportagem do jornal Folha de São Paulo, o Brasil é o segundo país no ranking mundial de cirurgias plásticas em adolescentes. A Sociedade Brasileira de Cirurgia Plástica estima um aumento, nos últimos três anos, de 300\% no número de cirurgias para colocação de próteses mamárias (COLLUTI, 2005).

2 Sobre a representação dos corpos de meninas em revista ilustrada destinada a esse público, conferir o trabalho de Figueira e Goellner (2003). A respeito das revistas que tomam o corpo e o embelezamento como tema, consultar Castro (2003).

3 Para esse autor, existem três tipos ideais de freqüentadores do sexo masculino nas academias, todos correspondentes ao conjunto de características corporais que comportam. O fisiculturista, indivíduo dotado de excesso de massa muscular, presente, geralmente, em número reduzido nas academias. O veterano, que seria o ideal típico 
de físico masculino, aproximando-se a uma harmonia das formas atléticas, sendo encontrado em maior número nas academias que o fisiculturista. O comum, sem massa muscular aparente, não se aproximando do ideal atlético de nenhum dos dois tipos citados acima, encontra-se em maior número nas academias. Apoiado em Max Weber, o autor lembra que esses tipos ideais não existem de forma pura na realidade, são apenas construções abstratas para uma melhor compreensão do contexto em que o tema está inserido.

4 As principais características dos tipos ideais femininos seriam: a) freqüentadoras comuns: são aquelas que não apresentam uma definição muscular aparente, possuem gordura localizada, não têm coxas e glúteos bem delineados, ou seja, apresentam vários sinais de gordura corporal; b) veteranas: possuem coxas delineadas, glúteos volumosos, cintura com ausência de barriga e abdômen definido, enfim um corpo esculpido, com pouca presença de gordura corporal; c) fisiculturistas: seria aquela com um volume muscular mais avantajado, com algumas formas masculinas, a chamada hipermusculosa. No entanto, talvez esse último tipo ideal seja pouco adequado no que tange o público feminino que freqüenta academias, especialmente no campo pesquisado, uma vez que não identificamos nenhuma mulher com essas características.

5 Um exemplo extraído de nosso diário de campo é bastante ilustrativo a esse respeito: "Durante uma aula de Body Combat, o professor pergunta às alunas se elas gostariam de queimar 100 calorias a mais. Elas respondem que sim, e o professor então afirma que para isso elas deveriam realizar o 'feitiço' que ele passaria, que além de 'queimar' as referidas calorias, reduziria a celulite e a gordura localizada no abdômen. $\mathrm{O}$ 'feitiço' consistia em alguns movimentos que se assemelhavam aos gestos do Katá (Caratê), sendo que todas as alunas fizeram".

\section{REFERÊNCIAS}

CASTRO, A. L. de. Culto ao corpo e sociedade: mídia, estilos de vida e cultura de consumo. São Paulo: Fapesp/Anablume, 2003.

COLlUTI, C. País é $2^{\circ}$ em plástica de jovens. Folha de São PauloCotidiano, 16/01/2005. Disponível em: <http://www1.folha.uol.com. br/fsp/cotidian/ff1601200518.htm>. Acesso em: 15 abr. 2005. 
FIGUEIRA, M. L. M.; GOELLNER, S. V. Representações de corpos adolescentes femininos contemporâneos: saúde, beleza e moda na revista capricho. In: Pré-CONBRACE Sul, 1., 2003, Pato Branco. Anais.... Pato Branco: CBCE/PR-CBCE/SC-CBCE/RS-FADEP, 2003.

HANSEN, R.; VAZ, A. F. Treino, culto e embelezamento do corpo: um estudo em academias de ginástica e musculação. $R C B C E$, Campinas, v. 26, n. 1, p. 135-152, set./2004.

SABINO, C. Musculação: expansão e manutenção da masculinidade. In: GOLDENBERG, M. (Org.). Os novos desejos: das academias às agências de encontro. Rio de Janeiro: Record, 2000. p. 61-103.

SANT'ANNA, D. B. Cuidados de si e embelezamento feminino: fragmentos para uma história do corpo no Brasil. In: (Org.). Politicas do corpo. São Paulo: Estação Liberdade, 1995. p. 121-139.

. Identidade Corporal. Corpo Prazer e Movimento, São Paulo, 2002, p. 24-31.

SILVA, A. S. da. Educação e culto do corpo na sociedade contemporânea: saúde, "embelezamento", performance. Florianópolis: DAP/ PRPG/UFSC, 2003. (Relatório de pesquisa).

VAZ, A. F. Técnica, Esporte, Rendimento. Movimento, Porto Alegre, v. 7, p. 87-99, 2001.

Recebido: 30 de março de 2007

Aprovado: 16 de abril de 2007

Endereço para correspondência:

gi.torri@bol.com.br 